\title{
Self-assembled silk fibroin nanoparticles loaded with binary drugs in the treatment of breast carcinoma
}

\author{
This article was published in the following Dove Press journal: \\ International Journal of Nanomedicine \\ 2 September 2016 \\ Number of times this article has been viewed
}

\author{
Hui $\mathrm{Li}^{1, *}$ \\ Jian Tian ${ }^{1,2, *}$ \\ Anqing $\mathrm{Wu}^{2}$ \\ Jiamin Wang' \\ Cuicui $\mathrm{Ge}^{2}$ \\ Ziling Sun ${ }^{1-3}$ \\ 'School of Biological and Basic \\ Medical Science, ${ }^{2}$ School of \\ Radiological \& Interdisciplinary \\ Sciences, Soochow University, \\ ${ }^{3}$ Collaborative Innovation Center of \\ Radiation Medicine of Jiangsu Higher \\ Education Institutions, Suzhou, Jiangsu, \\ People's Republic of China \\ *These authors contributed equally \\ to this work
}

Correspondence: Ziling Sun

School of Biological and Basic

Medical Science, Soochow University,

No 199 Ren'ai Road, Industrial Park,

Suzhou 215I23, People's Republic of

China

Tel +865I2 65880108

Email sunziling@suda.edu.cn

Jiamin Wang

School of Biological and Basic

Medical Science, Soochow University,

No 199 Ren'ai Road, Industrial Park,

Suzhou 215I23, People's Republic

of China

Tel +865I265880I08

Email wangjiamin@suda.edu.cn

\begin{abstract}
Self-assembled nanoparticles of the natural polymer, silk fibroin (SF), are a very promising candidate in drug delivery due to their biocompatible and biodegradable properties. In this study, SF nanoparticles loaded with 5-fluorouracil (5-FU) and curcumin with size $217 \pm 0.4 \mathrm{~nm}$ and with a loading efficacy of $45 \%$ and $15 \%$ for 5 -FU and curcumin, respectively, were prepared. The in vitro release effect of 5-FU and curcumin from nanoparticles was evaluated as $\sim 100 \%$ and $\sim 5 \%$, respectively. It has been revealed that the application of such a nanodrug can increase the level of reactive oxygen species, which in turn induces apoptosis of cancer cells in vitro. Animal studies have shown that tumors could be noticeably reduced after being injected with the drug-entrapped nanoparticles. More apoptotic cells were found after 7 days of treatment with SF nanoparticles by a hematoxylin-eosin staining assay. These results demonstrate the future potential of nanoparticle-loaded binary drugs in the treatment of breast cancer.
\end{abstract}

Keywords: silk fibroin nanoparticles, 5-flurouracil, curcumin, reactive oxygen species

\section{Introduction}

Breast carcinoma is one of the leading causes of death worldwide, and its rate of incidence is increasing every year. ${ }^{1-3}$ Many strategies have been developed for cancer diagnosis ${ }^{4}$ and therapy, such as immunotherapy, thermal therapy, phototherapy, surgery, gene therapy, chemotherapy, and radiotherapy. ${ }^{5-11}$ Each of these methods has its own advantages and disadvantages. ${ }^{12}$ Although small molecules have been used for chemotherapy for many years, there are several disadvantages, including poor water solubility, nonspecific targeting and misdistribution, and drug resistance shortly after initial treatment. These disadvantages hinder their efficiency and effect in treating cancers. Recently, delivery of these small molecules by using nanoparticles has been rapidly developed, which offers a new chance for cancer treatment in the preclinical or clinical phases. ${ }^{13,14}$ The unique properties of nanoparticles could overcome the limitations of using small molecules as therapeutic agents in biomedical applications. ${ }^{15}$ For example, the uptake of drug could be enhanced by the "enhanced permeability and retention effect", ${ }^{16}$ which can increase the drug accumulation in target cancer tissues and reduce the efflux pump-mediated drug resistance. Besides, capsuled by nanoparticles, the solubility and half-life of small molecular drugs can be improved with controllable releasing behaviors.

Curcumin is a natural compound with diphenolic groups derived from turmeric Curcuma longa, which is widely used in chemotherapy/radiosensitizing of cancer ${ }^{17-19}$ and other biomedical fields ${ }^{20,21}$ with almost no toxicity, ${ }^{22,23}$ which has potential as a promising candidate in clinical trials for cancer treatment. However, owing to its poor submit your manuscript

Dovepress

15 in 0 
solubility in physiological environment, curcumin often shows a low level of absorption inside the gut, and the amount of curcumin that reaches the tissues outside the gut is pharmacologically insignificant as per the measurements of blood plasma levels and biliary excretion. ${ }^{24} 5$-Fluorouracil (5-FU) is another highly efficient chemotherapeutic agent that inhibits the methylation reaction of deoxyuridylic acid to thymidylic acid. $^{25,26}$ This chemical drug can cause intense thymine deficit in the cells by interfering with the synthesis of deoxyribonucleic acid and ribonucleic acid, which eventually results in an imbalanced growth and death of cancer cells. To increase their water solubility and biocompatibility, several drug carriers are developed based on nanotechnology, ${ }^{27}$ ranging from liposome, ${ }^{28}$ proteins, ${ }^{29}$ saccharides,${ }^{30}$ phospholipids, ${ }^{31}$ to inorganic silica particles ${ }^{32,33}$ and polymeric organic nanoparticles. ${ }^{34-36}$ Besides, the slow and controllable release of drugs is helpful in providing a sustainable dose at a therapeutic level, which benefits the improved efficiency and safety. Recently, curcumin when encapsulated with silk fibroin (SF) nanoparticles and administered to breast cancer cells was observed to have a greatest entrapment, intracellular uptake, and controlled release. ${ }^{29}$ Moreover, it has also been revealed that administration of two or more drugs concomitantly is also important in cancer treatment.

Owing to its biocompatible and biodegradable properties, natural polymer SF is considered to be a very promising candidate in biomedical fields. ${ }^{37-42}$ As a drug carrier, the SF molecules possess controllability of their degradation under in vitro and in vivo, which can be regulated by changing its size, crystallinity, molecular weight, and degree of cross-linking. ${ }^{43,44}$ The hydrophobic amino acid residues in SF molecules, such as alanine, glycine, and tyrosine, can enhance the entrapping of curcumin and 5-FU through hydrophobic interaction and $\pi-\pi$ packing, which increase the loading efficacy of the binary drug carrier. Besides, the hydrophilic amino acid residues in SF molecules, such as serine, aspartic acid, and glutamate, increase their water solubility and induce the formation of nanoparticles in aqueous solutions. These properties make SF molecules a good candidate as drug carrier. ${ }^{45}$ In this study, we developed SF nanoparticles as a degradable and biocompatible carrier for loading and delivering binary drugs curcumin and 5-FU, which showed an excellent anticancer performance in vitro and in vivo.

\section{Materials and methods}

Preparation of 5-FU and curcumin loaded with nano-SF particles

$\mathrm{SF}$ aqueous solution was prepared as previously described. ${ }^{46}$ Bombyx mori domestic silk was treated with $\mathrm{Na}_{2} \mathrm{CO}_{3}$ solution to remove sericin. Briefly, $80 \mathrm{~g}$ of raw silk fibers was degummed three times in $4,000 \mathrm{~mL}$ of $0.075 \%$ sodium carbonate and then rinsed thoroughly with deionized water. After drying in an oven at $60^{\circ} \mathrm{C}$, the extracted $\mathrm{SF}$ was dissolved in 9.3 $\mathrm{M} \mathrm{LiBr}$ solution at $60^{\circ} \mathrm{C}$ for 4 hours. About $8.0 \%$ (w/v) SF solution was obtained after 4 days of dialysis in deionized water, which was followed by filtration. Curcumin and 5-FU were obtained from Aladdin Industrial Corporation of China and Sangon Biotechnological Group (Shanghai, People's Republic of China), respectively.

Curcumin $(1 \mathrm{mg} / \mathrm{mL})$ and 5-FU $(1 \mathrm{mg} / \mathrm{mL})$ were dissolved in alcohol; 5-FU solution was added into 1\% SF solution in drops and then curcumin solution was also added into the mixed solution in drops. 5-FU and curcumin nanoparticles that were loaded with SF were prepared by stirring for 1 day; then they were centrifugated at 12,000 rpm for 30 minutes and dialyzed for 24 hours.

\section{Morphology and structure of nanoparticles}

Nanoparticles were observed through a transmission electron microscope (Tecnai ${ }^{\mathrm{TM}}$ G2 Spirit BioTwin; FEI Company, Hillsboro, OR, USA) at a magnification of $120 \mathrm{kV}$. Briefly, a drop of aqueous solution of lyophilized solutions $(5 \mathrm{mg} / \mathrm{mL})$ was placed on a bronze ring membrane. The samples were air dried at room temperature before loading onto the microscope.

Fourier transform infrared spectroscopy was performed with Scimitar 1000 (VARIAN Medical Systems, Inc, Palo Alto, CA, USA). The wave number ranged from 200 to $4,000 \mathrm{~cm}^{-1}$ and the distinguished ability was $2.0 \mathrm{~cm}^{-1}$.

\section{Dynamic light scattering measurements}

Dynamic light scattering measurements for determining the average size and size distribution of the polymeric micelles were performed using a Nanosizer 90ZS (Malvern Instruments, Malvern, UK). The solution was filtered with membrane extruder having an average pore size of $0.2 \mathrm{~mm}$ (Lipex Biomembranes Inc., Vancouver, Canada). All the data analyses were performed in automatic mode. Measured size was presented as the average value of 20 runs, with triplicate measurements within each run.

\section{Drug loading content of nanoparticles, encapsulation efficiency, and release effect}

To determine the encapsulation efficiency (EE), $2 \mathrm{~mL}$ of nanoparticles was dispersed in $\mathrm{LiBr}$ and the absorbance was measured at 265 and $425 \mathrm{~nm}$. For comparison purposes, UVvis (ultraviolet-visible) spectra of SF solution, free curcumin, and free 5-FU were also used. 
To determine the release effect, $2 \mathrm{~mL}$ of nanoparticles was added to $18 \mathrm{~mL}$ of phosphate-buffered saline (PBS) and shaken at a rate of $120 \mathrm{rpm}$ at $37^{\circ} \mathrm{C}$. The medium $(2 \mathrm{~mL})$ released was collected for measurement at a specified time and $2 \mathrm{~mL}$ of fresh buffer was added again. A dialysis bag with a molecular weight of 3,500 was cut for dialyzing the free drugs to the outside medium.

The controllable releasing capability was determined by standard curve method. The releasing percentage of the two drugs is defined as the concentration of the ratio of dialyzed solution to the saturated loading concentration inside the nanoparticles. The amounts of 5-FU and curcumin released from nanoparticles were determined by measuring their absorbance at 265 and $425 \mathrm{~nm}$, respectively.

The drug $E E$ was calculated by the following equation: $E E=m_{\mathrm{d}, \mathrm{n}} / m_{\mathrm{d}, \mathrm{f}} \times 100 \%$, where $m_{\mathrm{d}, \mathrm{n}}$ and $m_{\mathrm{d}, \mathrm{f}}$ are the weight of the drug in nanoparticles and the feeding drugs, respectively. According to a previous report, ${ }^{47}$ the cumulative content of the drugs released can be calculated by the following equation:

$$
R \%=V_{e} \sum_{1}^{n-1} C_{i}+V_{0} C_{n}
$$

where $V_{e}$ is the volume of the released solution collected at each time point $(2 \mathrm{~mL}), V_{0}$ is the volume of original buffer solutions $(18 \mathrm{~mL}), C_{i}$ is the drug concentration in the released medium at displacement time $i$, and $n$ is the total number of displacement. $C_{n}$ is the final concentration in the released medium.

\section{TI culture}

The 4T1 cells (murine breast cancer cells) were cultured in standard cell media as recommended by the American Type Culture Collection (ATCC) in RPMI-1640 medium containing $10 \%(\mathrm{v} / \mathrm{v})$ fetal bovine serum and $1 \%$ penicillinstreptomycin (Thermo Fisher Scientific, Waltham, MA, USA) at $37^{\circ} \mathrm{C}$ in $5 \% \mathrm{CO}_{2}$ humidified incubator.

\section{Cell apoptosis analysis by flow cytometry}

$4 \mathrm{~T} 1$ cells were cultured at $2 \times 10^{5}$ cells for 1 day, and then fibroin loaded-curcumin and 5-FU nanoparticles, control and free curcumin and $5-\mathrm{FU}$ at $37^{\circ} \mathrm{C}$ for $48 \mathrm{~h}$ respectively were added. The cells were harvested by trypsinization and washed twice with PBS. The cells were centrifugated at $800 \mathrm{rpm}$ for 5 minutes and added to PE Annexin V Apoptosis Detection Kit I (BD Bioscience, San Jose, CA, USA) at room temperature for 1 hour. The cell suspension was then analyzed with FACSVerse $^{\mathrm{TM}}$ flow (BD Bioscience).

\section{Reactive oxygen species}

The reactive oxygen species (ROS) contents were measured by flow cytometry. Briefly, $4 \mathrm{~T} 1$ cells $\left(2 \times 10^{5} /\right.$ well $)$ were cultured on dishes and allowed to grow overnight, and then curcumin and 5-FU loaded with nano-fibroin and free curcumin and 5-FU were added at specified concentrations to dishes. The cells were digested with trypsinization after 24 hours of drug-loaded nanoparticles treatment and then stained by $2^{\prime}, 7^{\prime}$-dichlorofluorescin diacetate (DCFH-DA) (Beyotime Biotech, Nantong, People's Republic of China) at $37^{\circ} \mathrm{C}$ for 30 minutes. Flow cytometry was used for detecting the fluorescence of the oxidizing by-product, dichlorodihydrofluorescei (DCF) under the laser of $488 \mathrm{~nm}$ UV light. The fluorescence was analyzed using FACSVerse ${ }^{\mathrm{TM}}$ flow (BD Bioscience).

\section{In vivo experiment}

$4 \mathrm{~T} 1$ cells were harvested at $1 \times 10^{6}$ cells and $100 \mu \mathrm{L}$ was injected into the abdomens of SPF BALB/C mice aged 5-8 weeks. Thirty mice bearing 4T1 tumor tissues for 1 week $(7.5 \mathrm{~mm})$ were divided into control, free group, and nano group. A total of $100 \mu \mathrm{L}$ of nanoparticle-loaded drug, free curcumin, and 5-FU, whose concentration was $450 \mu \mathrm{g} / \mathrm{mL}$, were percutaneously intra-tumor injected. The size of the tumor tissues was observed after 3, 5, and 7 days of treatment. Some tissues were prepared for hematoxylin-eosin staining.

All animal experiments were conducted in accordance with Management Ordinance of Experimental Animal of China ([2001] No 545) and approved by the Jiangsu Province in experimental animals management rules ([2008] No 26).

\section{Results}

Figure 1 shows the physical characterization of the SF nanoparticles loaded with 5-FU and curcumin. The typical transmission electronic microscopic image (Figure 1A) revealed that the SF molecules conjugate with each other to form nanoparticles with a size of 50-250 nm (Figure 1B). The hydrodynamic diameter $\left(D_{\mathrm{h}}\right)$ obtained by dynamic light scattering shows that the average $D_{\mathrm{h}}$ is $217 \pm 0.4 \mathrm{~nm}$, with a polydistribution index of $0.049-0.059$, and thereby nanoparticles disperse well in aqueous environment.

The characterizations of SF nanoparticles studied by the Fourier transform infrared spectroscopy are shown in Figure 1C. The results show that SF nanoparticles did not undergo any change compared to pure SF, which emphasizes that the chemical bonding remained unchanged after the SF nanoparticles were loaded with the drugs. The characteristic peak of 5-FU group was found in the following regions of SF nanoparticles, 3,000-2,900 $\mathrm{cm}^{-1}$ (-C-H stretching), 
A

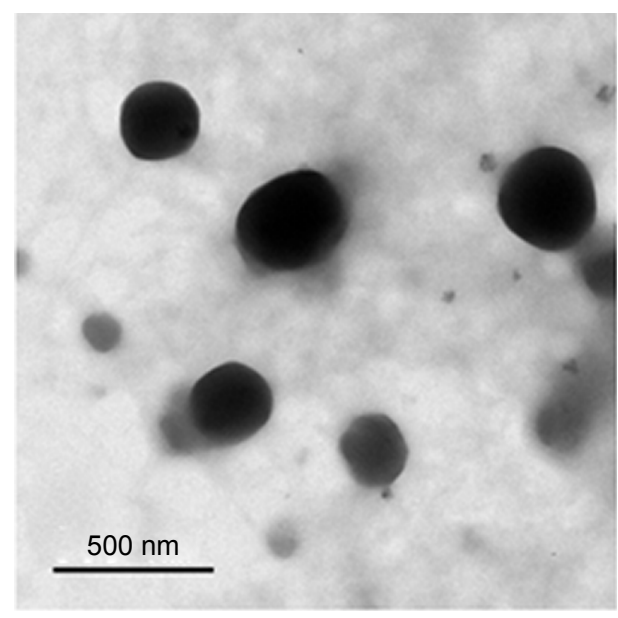

\section{C}

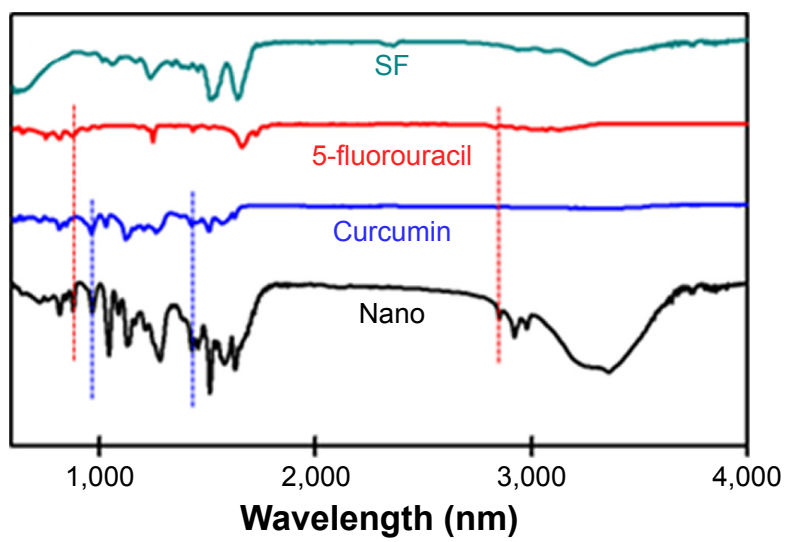

B

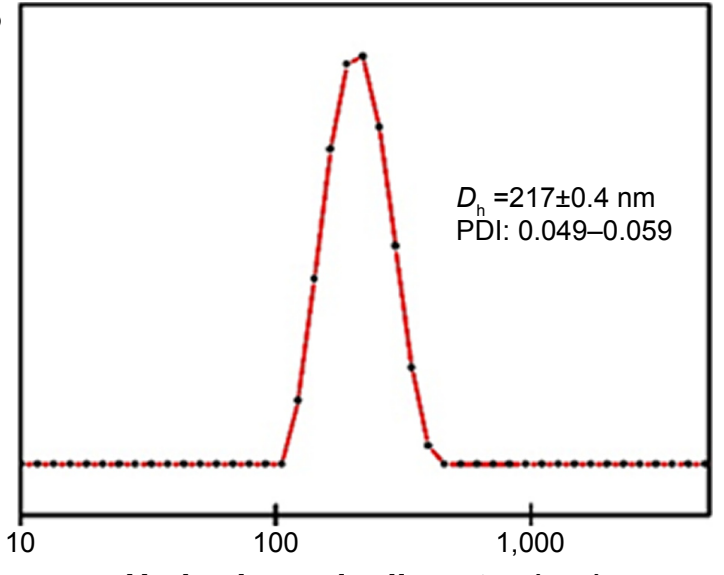

Hydrodynamic diameter $(\mathrm{nm})$
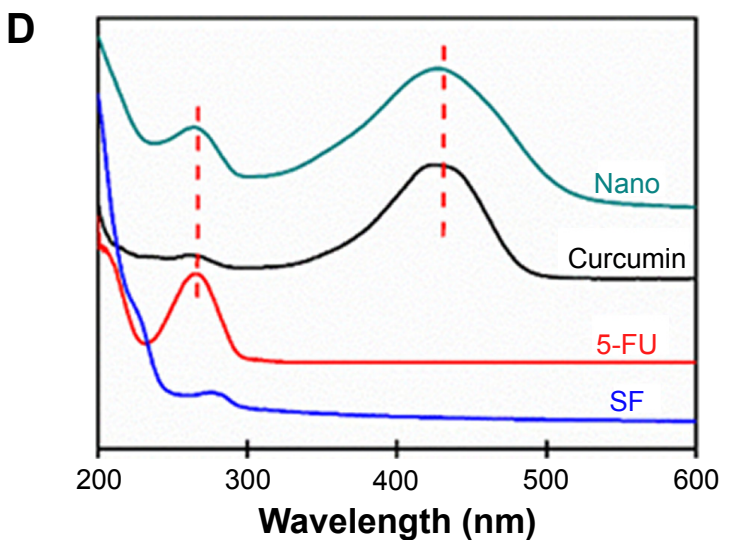

Figure I Characterization of silk fibroin (SF) nanoparticles after loading with 5-fluorouracil (5-FU) and curcumin.

Notes: (A) TEM and (B) hydrodynamic diameter obtained by DLS. (C) FTIR. (D) UV-vis curve of the binary drug-loaded nanoparticles (Nano), free curcumin, free 5-FU, and SF, respectively.

Abbreviations: TEM, transmission electron microscopy; FTIR, Fourier transform infrared spectroscopy; UV-vis, ultraviolet visible spectroscopy; DLS, dynamic light scattering.

$1,425 \mathrm{~cm}^{-1}$ corresponding to the $-\mathrm{C}=\mathrm{N}$ and $-\mathrm{C}=\mathrm{C}$ ring stretching vibrations, and pyrimidine band at $1,246 \mathrm{~cm}^{-1}$. Curcumin showed its characteristic group absorption peaks in sharp absorption bands at $1,605 \mathrm{~cm}^{-1}, 1,502 \mathrm{~cm}^{-1}(-\mathrm{C}=\mathrm{O}$ and $-\mathrm{C}-\mathrm{C}$ vibrations), $1,435 \mathrm{~cm}^{-1}$ (olefinic $-\mathrm{C}-\mathrm{H}$ bending vibration), and $1,285 \mathrm{~cm}^{-1}$ (aromatic $-\mathrm{C}-\mathrm{O}$ stretching vibration).

The UV-vis spectrum also reveals that 5-FU $(265 \mathrm{~nm})$ and curcumin $(425 \mathrm{~nm})$ were successfully loaded into the fibroin nanoparticles (Figure 1D). The drug contents of the nanoparticles were measured and compared with the feeding drug content by UV-vis spectrum, which yielded the value of drug EE. The result shows that the drug was successfully loaded into the nanoparticles by self-assembly, with an EE value of $45 \%$ and $15 \%$ for 5 -FU and curcumin, respectively. As shown in Figure 2, the release rate of SF nanoparticles was up to $\sim 100 \%$ and $\sim 5 \%$ for 5 -FU and curcumin, respectively.

To verify the efficacy of drug-loaded nanoparticles in treating cancer, their effectiveness was first evaluated at cellular level, by examining the cellular morphological changes and sensitivity toward cell apoptosis. The morphology of the cells was found to be normal; cells of the control group grew well for 2 days (Figure 3A), whereas the cells incubated with free 5-FU and curcumin group suffered slight

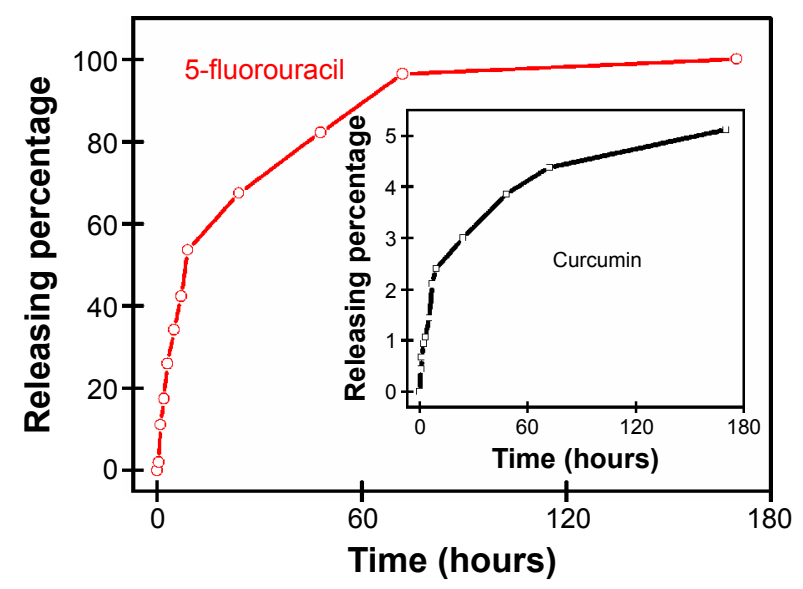

Figure 2 Releasing percentage of 5-fluorouracil and curcumin from silk fibroin nanoparticles. 

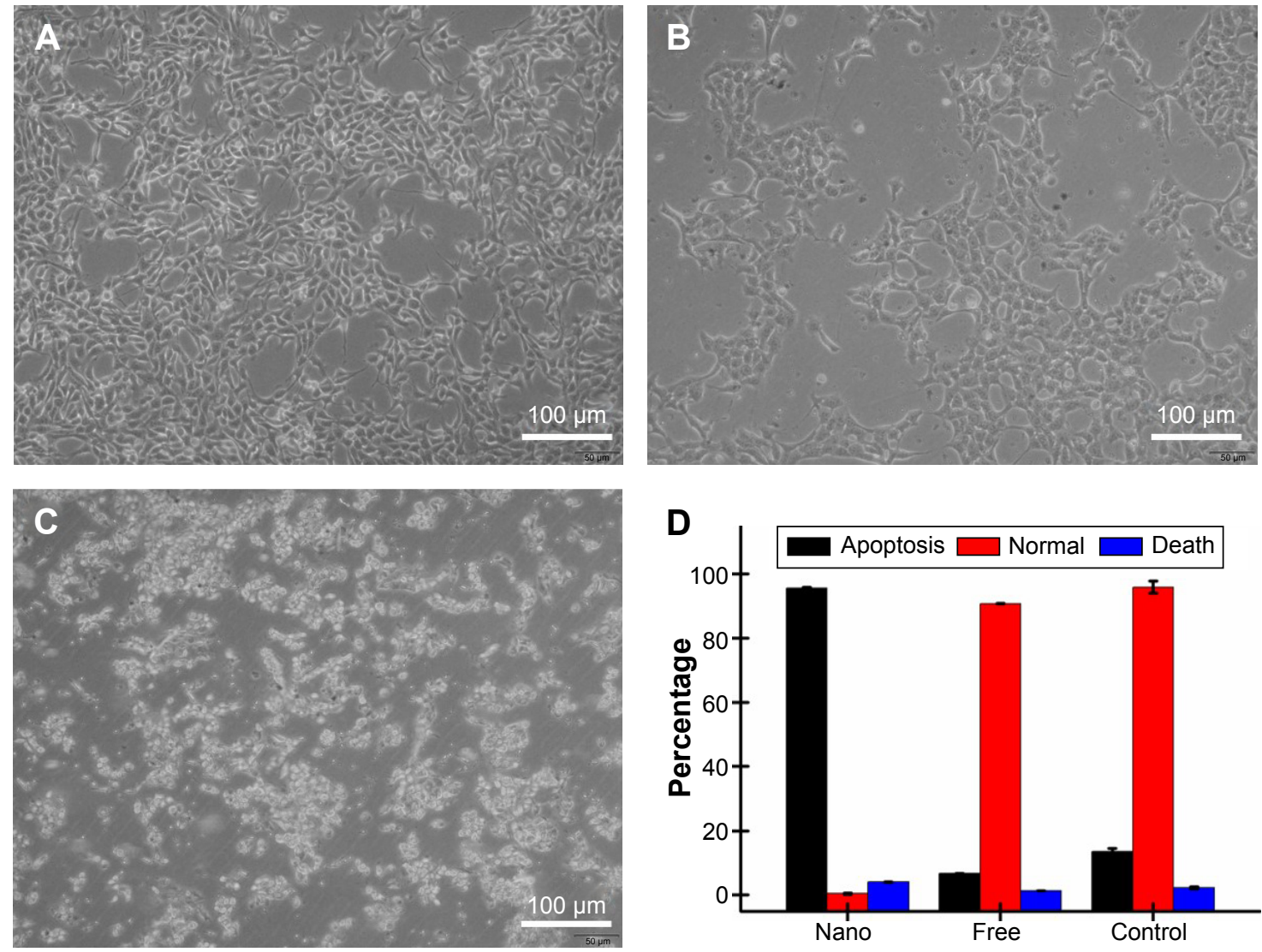

Figure 3 Morphologies of 4TI cells after incubation with (A) control, (B) free 5-fluorouracil and curcumin, and (C) drug-loaded nanoparticles, respectively. (D) Flow cytometry results that show the apoptosis of 4TI cell lines at same incubating conditions, (Magnification 100x).

apoptosis (Figure 3B). The cells incubated with drug-loaded nanoparticles suffered serious apoptosis after 2 days of culture, and their shape changed from spindle form to spherical form (Figure 3C). These results indicate that the drug-loaded nanoparticles exhibited chemotherapeutic effect toward the $4 \mathrm{~T} 1$ cells. These results were further confirmed by apoptosis assay. As shown in Figure 3D, the statistical percentage of cell apoptosis of drug-loaded nanoparticles was more than $90 \%$, which was much more than that for free drugs ( $\sim 8 \%)$ and control $(\sim 2 \%)$.

The ROS level was determined by the fluorescence intensity of DCFH-DA. As shown in Figure 4, the fluorescence intensity was found to be $33 \pm 2$ and $22 \pm 1$ for the drug-free nanoparticles and free drugs, respectively. The ROS level almost showed no change after incubating the cells with free drugs. In contrast, the ROS level became very high (323 \pm 12$)$ after incubating the cells with drug-loaded nanoparticles. ROS level in silk fibroin loading curcumin and 5-FU nanoparticles can be enhanced up to tenfold more than that of control. Other results show that drug-loaded nanoparticles group showed more apoptosis (Figure 3), which was probably due to the generation of ROS inside the cells.
The efficacy of the drug-loaded nanoparticles in the treatment of cancer was further investigated in vivo. The binary drug-loaded nanoparticles were injected into tumor-loaded mice and the size of tumor was then measured. As shown in Figure 5A, the binary drug-loaded nanoparticles obviously reduced the size of tumors. In contrast, the tumor size

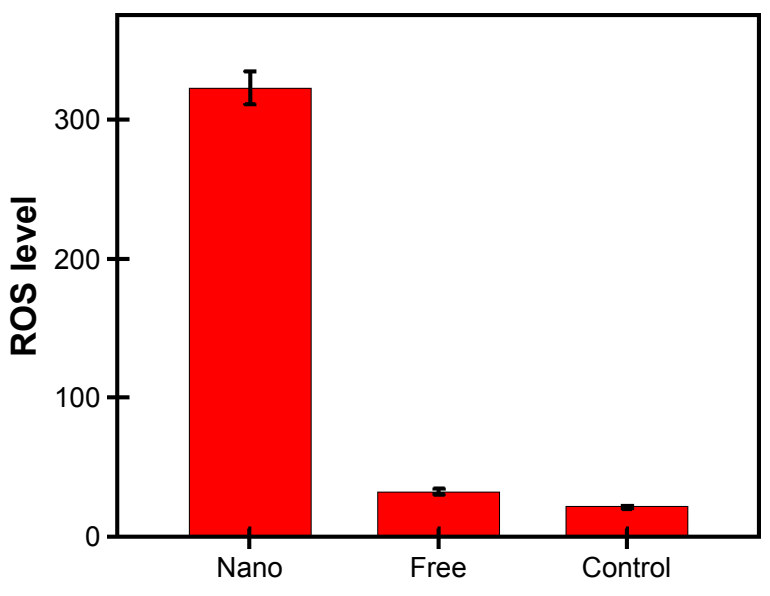

Figure 4 Increase in the intracellular level of ROS observed after the 4TI cell lines were incubated with drug-loaded nanoparticles compared to free 5-fluorouracil and curcumin, respectively.

Abbreviation: ROS, reactive oxygen species. 
A

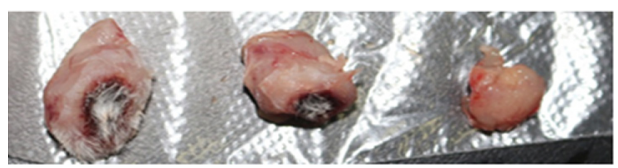

B
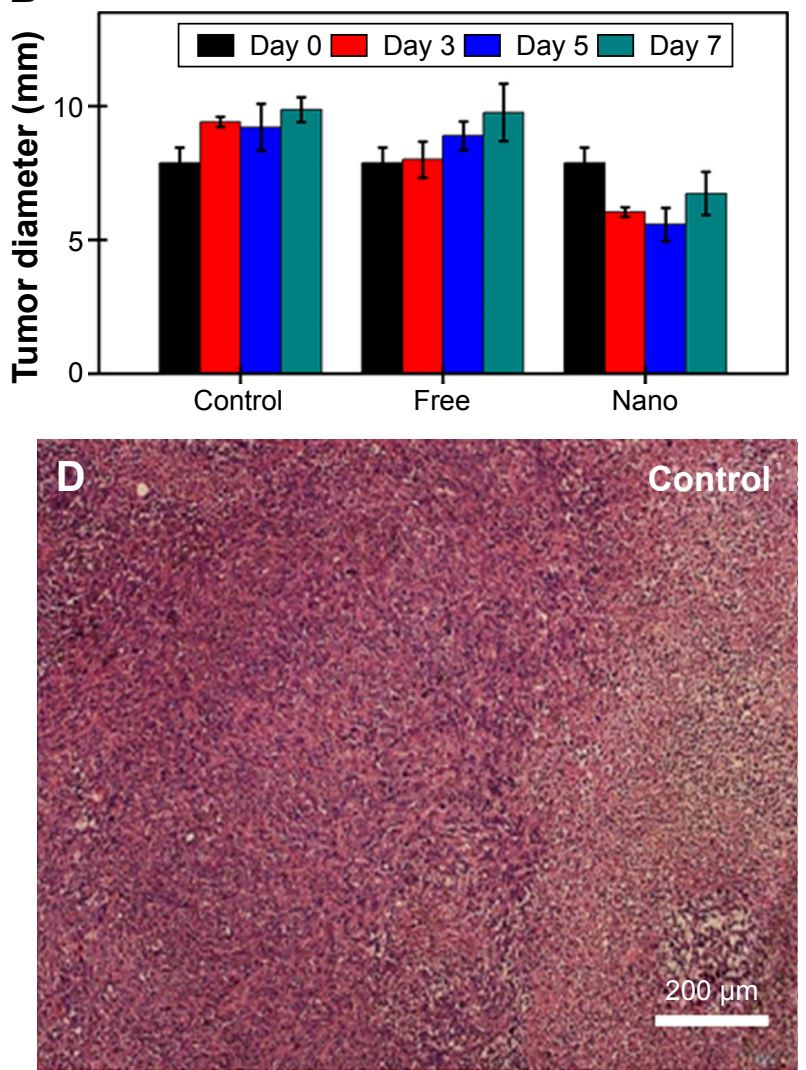
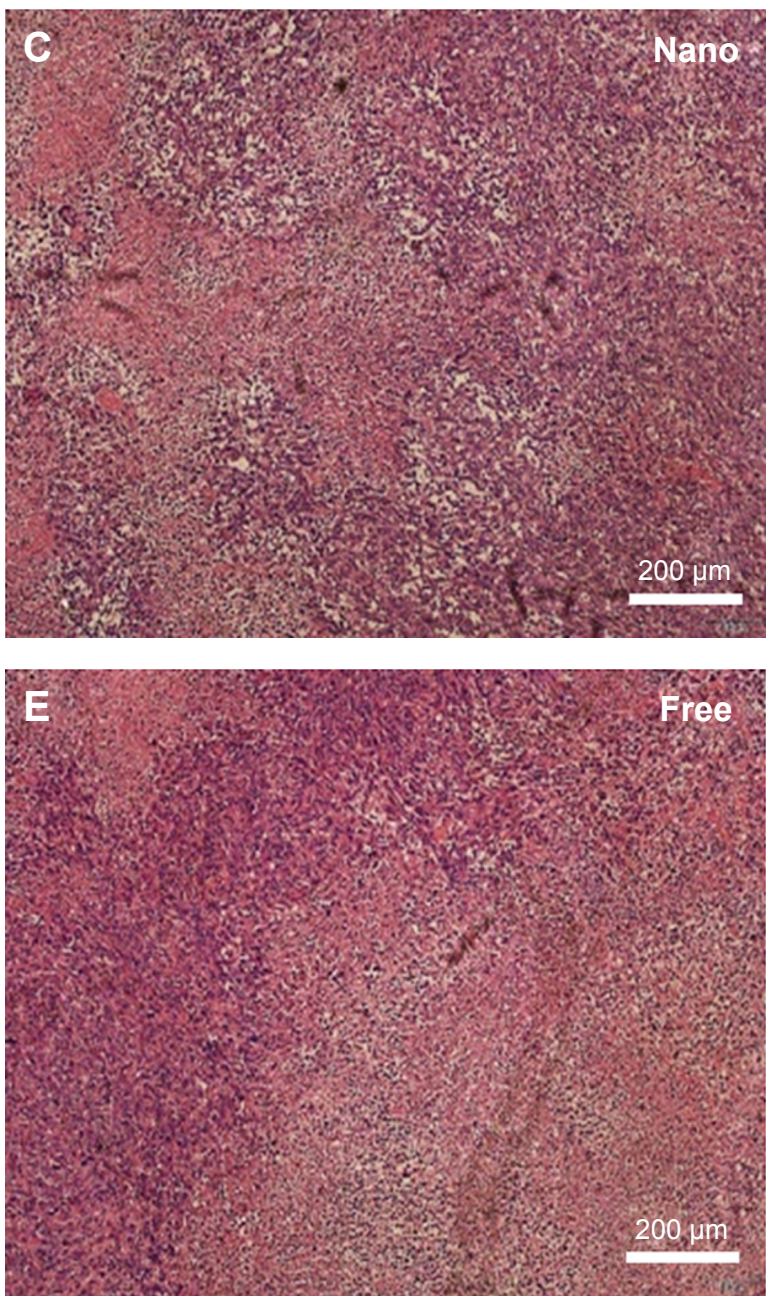

Figure 5 Changes after treatment with drugs in size and histochemistry.

Notes: (A) Optical image that shows the tumor reduction in mice injected with nanoparticle-loaded drugs. (B) Statistic analysis of tumor diameter observed in groups administered with free binary drug, nanoparticle-loaded binary drug, and control (PBS buffer). (C-E) HE staining of tumor tissues. Magnification I00X.

Abbreviations: PBS, phosphate-buffered saline; HE, hematoxylin-eosin.

was reduced to a little extent when treated with free drug, and almost no changes can be observed compared with the control group. Measurement of tumor size from the three experimental groups, as shown in Figure 5B, showed that injection of drug-entrapped nanoparticles reduced the tumor size on the third and fifth days, but slightly increased on the seventh day. In contrast, the treatment of free drug only shows the reduced increscent of tumor and the increscent again accelerate for 5-7 days. These comparisons indicate that entrapment of 5-FU and curcumin into SF nanoparticles exhibited efficacy in in vivo treatment of breast cancer. No injection was given after 7 days - the mice in the control group died after 25 days of injection, in free-drug group after 33 days, and in nano-group after 45 days. To assess whether SF nanoparticles induced tissues apoptosis, we evaluated the tumor sections histologically by H\&E. More apoptotic cells were found in the group treated with SF nanoparticles
(Figure 5C) after 7 days of treatment compared to those in free group or control group (Figure 5D and E).

\section{Discussion}

The drug 5-FU is a chemotherapeutic agent highly effective in the treatment of cancer, which inhibits the methylation reaction of deoxyuridylic acid to thymidylic acid, the key repair process for reducing thymine deficits. ${ }^{25,26}$ Curcumin is widely used as an anticancer agent in preclinical and clinical trials, probably due to their capability of generating intracellular ROS. However, this drug is poorly soluble in water, which restricts it from being directly used in aqueous solutions. On being carried by SF nanoparticles with welldispersion capacity, more drugs can exist inside aqueous solutions, which can then increase the effectiveness of the drugs in treating cancer cells and in vivo tumor cells via incubation or injection. In addition, curcumin enhances 
the solubility of 5-FU inside the nanoparticles through $\pi-\pi$ packing. Although the cumulative release of curcumin is less, all curcumin will be released from SF nanoparticles in a stepwise process as a result of degradation.

In comparison with the free drugs, the nanoparticleloaded drug can help a larger amount of drugs enter the cells or tumor tissue with controllable releasing capability. This possibly induces the apoptosis of cancer cells (or decreases the cell variability). A previous report ${ }^{48}$ also has found a similar result. Apoptosis can be induced by the ROS generated after the administration of curcumin. ${ }^{49-52}$ ROS could act as a vital candidate pathway for inducing tumor cell apoptosis by targeting mitochondrial and endoplasmic reticulum stress-related death pathway. ${ }^{9}$ As a result, the releasing effect of these two drugs is comparable based on their mass percentage, which may help them in treating cancer cells. Our experimental results revealed that 5-FU and curcumin loaded with SF nanoparticles have an increased anticancer efficacy compared to free 5-FU and curcumin.

\section{Conclusion}

In conclusion, we used SF nanoparticles to entrap the binary drugs 5 -FU and curcumin to investigate their effectiveness on breast cancer in vivo and in vitro. The results showed significant improvement in the cytotoxic activity and bioavailability of SF nanoparticles compared to free curcumin and 5-FU. The anticancer effect observed may be induced by the apoptosis of cells via the generation of cellular ROS. Self-assembling polymer systems of SF-loaded 5-FU and curcumin will be a facile method for cancer treatment.

\section{Acknowledgments}

This study was supported by the Foundation for the Returned Overseas Chinese Scholars, State Education Ministry (K513401215), China Postdoctoral Science Foundation (2015M571809), Postdoctoral Fund of Jiangsu Province (7131707714), and the Priority Academic Program Development of Jiangsu Higher Education Institutions (YX13400212).

\section{Author contributions}

All authors contributed toward data analysis, drafting and revising the paper and agree to be accountable for all aspects of the work.

\section{Disclosure}

The authors report no conflict of interest in this work.

\section{References}

1. Estanqueiro M, Amaral MH, Conceição J, Sousa Lobo JM. Nanotechnological carriers for cancer chemotherapy: the state of the art. Colloids Surf B Biointerfaces. 2015;126:631-648.

2. Siegel RL, Miller KD, Jemal A. Cancer statistics, 2015. CA Cancer J Clin. 2015;65(1):5-29.

3. Sun L, Wu Q, Peng F, Liu L, Gong C. Strategies of polymeric nanoparticles for enhanced internalization in cancer therapy. Colloids Surf B Biointerfaces. 2015;135:56-72.

4. Duan R, Zuo X, Wang S, et al. Lab in a tube: ultrasensitive detection of microRNAs at the single-cell level and in breast cancer patients using quadratic isothermal amplification. $J$ Am Chem Soc. 2013;135(12): 4604-4607.

5. Jia X, Jia L. Nanoparticles improve biological functions of phthalocyanine photosensitizers used for photodynamic therapy. Curr Drug Metab. 2012;13(8):1119-1122.

6. Shao J, Dai Y, Zhao W, et al. Intracellular distribution and mechanisms of actions of photosensitizer zinc(II)-phthalocyanine solubilized in Cremophor EL against human hepatocellular carcinoma HepG2 cells. Cancer Lett. 2013;330(1):49-56.

7. Xu S, Liu J, Li D, et al. Fe-salphen complexes from intracellular $\mathrm{pH}-$ triggered degradation of $\mathrm{Fe}_{3} \mathrm{O}_{4} @$ Salphen-InIII CPPs for selectively killing cancer cells. Biomaterials. 2014;35(5):1676-1685.

8. Zhu J, Yang F, He F, Tian X, Tang S, Chen X. A tubular gelatin scaffold capable of the time-dependent controlled release of epidermal growth factor and mitomycin C. Colloids Surf B Biointerfaces. 2015; 135:416-424.

9. Zou P, Xia Y, Chen T, et al. Selective killing of gastric cancer cells by a small molecule targeting ROS-mediated ER stress activation. Mol Carcinog. 2016;55(6):1073-1086.

10. Liu Y, Chen C, Qian P, et al. Gd-metallofullerenol nanomaterial as non-toxic breast cancer stem cell-specific inhibitor. Nat Commun. 2015; 6:5988.

11. Tian J, Chen J, Ge C, et al. Synthesis of PEGylated ferrocene nanoconjugates as the radiosensitizer of cancer cells. Bioconjug Chem. 2016; 27(6):1518-1524.

12. Gao Y, Xie J, Chen H, et al. Nanotechnology-based intelligent drug design for cancer metastasis treatment. Biotechnol Adv. 2014;32(4): 761-777.

13. Biswas $\mathrm{S}$, Torchilin VP. Nanopreparations for organelle-specific delivery in cancer. Adv Drug Deliv Rev. 2014;66:26-41.

14. Farokhzad OC, Langer R. Impact of nanotechnology on drug delivery. ACS Nano. 2009;3(1):16-20.

15. Chen ZG. Small-molecule delivery by nanoparticles for anticancer therapy. Trends Mol Med. 2010;16(12):594-602.

16. Matsumura Y, Maeda H. A new concept for macromolecular therapeutics in cancer chemotherapy: mechanism of tumoritropic accumulation of proteins and the antitumor agent smancs. Cancer Res. 1986;46(12 Pt 1): 6387-6392.

17. Kuttan R, Sudheeran PC, Josph CD. Turmeric and curcumin as topical agents in cancer therapy. Tumori. 1987;73(1):29-31.

18. Liang G, Shao L, Wang Y, et al. Exploration and synthesis of curcumin analogues with improved structural stability both in vitro and in vivo as cytotoxic agents. Bioorg Med Chem. 2009;17(6):2623-2631.

19. Nardo L, Andreoni A, Bondani M, Másson M, Hjorth Tønnesen H. Studies on curcumin and curcuminoids. XXXIV. Photophysical properties of a symmetrical, non-substituted curcumin analogue. J Photochem Photobio B. 2009;97(2):77-86.

20. De R, Kundu P, Swarnakar S, et al. Antimicrobial activity of curcumin against Helicobacter pylori isolates from India and during infections in mice. Antimicrob Agents Chemother. 2009;53(4):1592-1597.

21. Pizzo P, Scapin C, Vitadello M, Florean C, Gorza L. Grp94 acts as a mediator of curcumin-induced antioxidant defence in myogenic cells. J Cell Mol Med. 2010;14(4):970-981.

22. Lao C, Ruffin M, Normolle D, et al. Dose escalation of a curcuminoid formulation. BMC Complement Altern Med. 2006;6:10. 
23. Shankar TN, Shantha NV, Ramesh HP, Murthy IA, Murthy VS. Toxicity studies on turmeric (Curcuma longa): acute toxicity studies in rats, guineapigs \& monkeys. Indian J Exp Biol. 1980;18(1):73-75.

24. Anand P, Kunnumakkara AB, Newman RA, Aggarwal BB. Bioavailability of curcumin: problems and promises. Mol Pharm. 2007;4(6): 807-818.

25. Chen A-Z, Pu X-M, Kang Y-Q, Liao L, Yao Y-D, Yin G-F. Preparation of 5-fluorouracil-poly(L-lactide) microparticles using solutionenhanced dispersion by supercritical $\mathrm{CO}_{2}$. Macromol Rapid Commun. 2006;27(15):1254-1259.

26. Cho YW, Lee JR, Song SC. Novel thermosensitive 5-fluorouracilcyclotriphosphazene conjugates: synthesis, thermosensitivity, degradability, and in vitro antitumor activity. Bioconjug Chem. 2005;16(6): 1529-1535.

27. Ge C, Tian J, Zhao Y, Chen C, Zhou R, Chai Z. Towards understanding of nanoparticle-protein corona. Arch Toxicol. 2015;89(4): 519-539.

28. Wang D, Veena MS, Stevenson K, et al. Liposome-encapsulated curcumin suppresses growth of head and neck squamous cell carcinoma in vitro and in xenografts through the inhibition of nuclear factor kappaB by an AKT-independent pathway. Clin Cancer Res. 2008;14(19):6228-6236.

29. Gupta V, Aseh A, Rios CN, Aggarwal BB, Mathur AB. Fabrication and characterization of silk fibroin-derived curcumin nanoparticles for cancer therapy. Int J Nanomedicine. 2009;4:115-122.

30. Yallapu MM, Jaggi M, Chauhan SC. Poly( $\beta$-cyclodextrin)/curcumin selfassembly: a novel approach to improve curcumin delivery and its therapeutic efficacy in prostate cancer cells. Macromol Biosci. 2010;10(10): 1141-1151.

31. Maiti K, Mukherjee K, Gantait A, Saha BP, Mukherjee PK. Curcuminphospholipid complex: preparation, therapeutic evaluation and pharmacokinetic study in rats. Int J Pharm. 2007;330(1-2):155-163.

32. Clifford NW, Iyer KS, Raston CL. Encapsulation and controlled release of nutraceuticals using mesoporous silica capsules. J Mater Chem. 2008;18(2):162-165.

33. Peng F, Su Y, Zhong Y, Fan C, Lee ST, He Y. Silicon nanomaterials platform for bioimaging, biosensing, and cancer therapy. Acc Chem Res. 2014;47(2):612-623.

34. Bhawana, Basniwal RK, Buttar HS, Jain VK, Jain N. Curcumin nanoparticles: preparation, characterization, and antimicrobial study. J Agric Food Chem. 2011;59(5):2056-2061.

35. Hu K, Zhou H, Liu Y, et al. Hyaluronic acid functional amphipathic and redox-responsive polymer particles for the co-delivery of doxorubicin and cyclopamine to eradicate breast cancer cells and cancer stem cells. Nanoscale. 2015;7(18):8607-8618.

36. Yallapu MM, Jaggi M, Chauhan SC. Scope of nanotechnology in ovarian cancer therapeutics. J Ovarian Res. 2010;3(1):1-10.

37. Seib FP, Herklotz M, Burke KA, Maitz MF, Werner C, Kaplan DL. Multifunctional silk-heparin biomaterials for vascular tissue engineering applications. Biomaterials. 2014;35(1):83-91.
38. Yan S, Zhang Q, Wang J, et al. Silk fibroin/chondroitin sulfate/ hyaluronic acid ternary scaffolds for dermal tissue reconstruction. Acta Biomater. 2013;9(6):6771-6782.

39. Shi P, Teh TK, Toh SL, Goh JC. Variation of the effect of calcium phosphate enhancement of implanted silk fibroin ligament bone integration. Biomaterials. 2013;34(24):5947-5957.

40. Zhang W, Chen J, Tao J, et al. The promotion of osteochondral repair by combined intra-articular injection of parathyroid hormonerelated protein and implantation of a bi-layer collagen-silk scaffold. Biomaterials. 2013;34(25):6046-6057.

41. Gu Y, Zhu J, Xue C, et al. Chitosan/silk fibroin-based, Schwann cellderived extracellular matrix-modified scaffolds for bridging rat sciatic nerve gaps. Biomaterials. 2014;35(7):2253-2263.

42. Ren YJ, Zhou ZY, Liu BF, Xu QY, Cui FZ. Preparation and characterization of fibroin/hyaluronic acid composite scaffold. Int J Biol Macromol. 2009;44(4):372-378.

43. Li M-Y, Zhao Y, Tong T, et al. Study of the degradation mechanism of Chinese historic silk (Bombyx mori) for the purpose of conservation. Polym Degrad Stab. 2013;98(3):727-735.

44. Seib FP, Jones GT, Rnjak-Kovacina J, Lin Y, Kaplan DL. pH-dependent anticancer drug release from silk nanoparticles. Adv Healthc Mater. 2013;2(12):1606-1611.

45. Zhang Q, Yan S, Li M. Silk fibroin based porous materials. Materials. 2009;2(4):2276.

46. Wu D, Zhang J, Wang J, Li J, Liao F, Dong W. Hesperetin induces apoptosis of esophageal cancer cells via mitochondrial pathway mediated by the increased intracellular reactive oxygen species. Tumour Biol. 2016;37(3):3451-3459.

47. Li L, Gu J, Zhang J, et al. Injectable and biodegradable $\mathrm{pH}-$ responsive hydrogels for Localized and sustained treatment of human fibrosarcoma. ACS Appl Mater Interfaces. 2015;7(15):8033-8040.

48. Chu Q, Xu H, Gao M, et al. Liver-targeting Resibufogenin-loaded poly(lactic-co-glycolic acid)-D-alpha-tocopheryl polyethylene glycol 1000 succinate nanoparticles for liver cancer therapy. Int J Nanomedicine. 2016;11:449-463.

49. Mulik RS, Monkkonen J, Juvonen RO, Mahadik KR, Paradkar AR. Transferrin mediated solid lipid nanoparticles containing curcumin: enhanced in vitro anticancer activity by induction of apoptosis. Int J Pharm. 2010;398(1-2):190-203.

50. Jacobson MD. Reactive oxygen species and programmed cell death. Trends Biochem Sci. 1996;21(3):83-86.

51. Syng-Ai C, Kumari AL, Khar A. Effect of curcumin on normal and tumor cells: role of glutathione and bcl-2. Mol Cancer Ther. 2004;3(9): 1101-1108.

52. Palit S, Kar S, Sharma G, Das PK. Hesperetin induces apoptosis in breast carcinoma by triggering accumulation of ROS and activation of ASK1/JNK pathway. J Cell Physiol. 2015;230(8):1729-1739.
International Journal of Nanomedicine

\section{Publish your work in this journal}

The International Journal of Nanomedicine is an international, peerreviewed journal focusing on the application of nanotechnology in diagnostics, therapeutics, and drug delivery systems throughout the biomedical field. This journal is indexed on PubMed Central, MedLine, CAS, SciSearch ${ }^{\circledR}$, Current Contents ${ }^{\circledR} /$ Clinical Medicine,

\section{Dovepress}

Journal Citation Reports/Science Edition, EMBase, Scopus and the Elsevier Bibliographic databases. The manuscript management system is completely online and includes a very quick and fair peer-review system, which is all easy to use. Visit http://www.dovepress.com/ testimonials.php to read real quotes from published authors. 